\title{
Impact of CFTR modulator use on outcomes in people with severe cystic fibrosis lung disease
}

\author{
Michal Shteinberg (i) $^{1,2}$ and Jennifer L. Taylor-Cousar ${ }^{3}$
}

Affiliations: ${ }^{1}$ Pulmonary Institute and CF Center, Carmel Medical Center, Haifa, Israel. ${ }^{2}$ B. Rappaport Faculty of Medicine, Technion-Israel Institute of Technology, Haifa, Israel. ${ }^{3}$ Divisions of Pulmonary, Critical Care and Sleep Medicine and Pediatric Pulmonary Medicine, National Jewish Health, Denver, CO, USA.

Correspondence: Michal Shteinberg, Pulmonology Institute, Carmel Medical Center, 7 Michal Street, Haifa 3436212, Israel. E-mail: michalsh@technion.ac.il

@ERSpublications

CFTR modulators are efficacious in improving lung function and exacerbations, even in advanced CF. However, adverse drug reactions and drug interactions are frequent. http://bit.ly/37aN81E

Cite this article as: Shteinberg M, Taylor-Cousar JL. Impact of CFTR modulator use on outcomes in people with severe cystic fibrosis lung disease. Eur Respir Rev 2020; 29: 190112 [https://doi.org/10.1183/ 16000617.0112-2019].

ABSTRACT Drug compounds that augment the production and activity of the cystic fibrosis (CF) transmembrane regulator (CFTR) have revolutionised CF care. Many adults and some children with CF suffer advanced and severe lung disease or await lung transplantation. While the hope is that these drug compounds will prevent lung damage when started early in life, there is an ongoing need to care for people with advanced lung disease. The focus of this review is the accumulating data from clinical trials and case series regarding the benefits of CFTR modulator therapy in people with advanced pulmonary disease. We address the impact of treatment with ivacaftor, lumacaftor/ivacaftor, tezacaftor/ivacaftor and elexacaftor/ tezacaftor/ivacaftor on lung function, pulmonary exacerbations, nutrition and quality of life. Adverse events of the different CFTR modulators, as well as the potential for drug-drug interactions, are discussed.

\section{Introduction}

The past decade has revolutionised the care of people with cystic fibrosis (CF). CF treatment is gradually moving from that directed towards treating consequences of resulting organ damage to therapies directed towards restoration of the function of the CF transmembrane regulator (CFTR), collectively referred to as CFTR modulators. This hopeful era follows decades of pre-clinical research focused at identifying small molecules that increase the chloride conductance of CFTR at the epithelial cell membrane (potentiators, such as ivacaftor (IVA)) as well as molecules that improve folding and trafficking of mutated CFTR protein (correctors, such as lumacaftor (LUM), tezacaftor (TEZ) and elexacaftor (ELX)). Further strategies that are in various stages of drug development are directed towards amplification of CFTR translation and prevention of premature termination of transcription (readthrough agents for premature termination codon CFTR mutations). Other strategies in development are gene editing and gene replacement.

It is anticipated by many that initiating CFTR modulator therapy will change the course of CF lung disease. Indeed, an important direction of clinical trials is extending the use of previously established therapies to increasingly younger age groups $[1,2]$, with the rationale that an early start of CFTR modulation may slow and even prevent progression of pulmonary and extrapulmonary complications [3].

This article has an editorial commentary: https://doi.org/16000617.0051-2020.

Provenance: Submitted article, peer reviewed.

Received: 24 Aug 2019 | Accepted after revision: 12 Nov 2019

Copyright CERS 2020. This article is open access and distributed under the terms of the Creative Commons Attribution Non-Commercial Licence 4.0 . 
However, the majority of existing patients today are adults, many of whom have advanced CF and suffer consequences of long-standing CFTR deficiency [4]. In some countries, severe CF may occur earlier, in childhood or youth. The consequences of long-standing CFTR deficiency include structural lung damage, chronic pulmonary infection with drug-resistant microorganisms and malnutrition, with debilitating symptoms and frequent hospitalisations necessitating intensive treatment. When facing people with advanced CF we may ask whether CFTR modulation therapy will be beneficial in this subgroup of people with advanced lung disease or if lung damage is too advanced and irreversible for CFTR modulation to affect. This issue is particularly important when considering the already high treatment burden in patients with advanced lung disease, and consequently the potential for adverse drug reactions and drug-drug interactions associated with polypharmacy (a frequent occurrence in people with severe CF), as well as the high cost of these newly developed drugs.

The focus of this review is to summarise the evidence regarding the efficacy of CFTR modulators in people with CF with severe disease. As survival in CF is mostly predicted by the pulmonary involvement [5], we will focus on severe pulmonary disease rather than patients with severe extrapulmonary manifestations. We review the evidence for efficacy of CFTR modulation in improving pulmonary function and exacerbations, nutritional status and quality of life, as well as adverse reactions resulting from CFTR modulator therapy in people with CF with severe disease and drug-drug interactions.

\section{Efficacy of CFTR modulators in people with advanced pulmonary disease}

The introduction of IVA treatment in people with gating mutations set high standards for the clinical efficacy of CF modulation [6]. The phase III trial by RAMSAY et al. [6] showed an increase in lung function of $>10 \%$ (absolute) over placebo in forced expiratory volume in $1 \mathrm{~s}\left(\mathrm{FEV}_{1}\right) \%$ pred and a $55 \%$ reduction in the frequency of pulmonary exacerbations. IVA treatment also resulted in an increase in weight and respiratory-related quality of life. In this trial, similar to subsequent clinical trials of CFTR modulators, inclusion criteria were $\mathrm{FEV}_{1} \%$ pred $40-90 \%$ at screening. However, between screening and randomisation some of the participants decreased their lung function to a value $<40 \%$, possibly reflecting natural fluctuations in lung function measurements, and people with CF included in the IVA trial had FEV $\%$ pred at randomisation as low as $31.6 \%$. These populations of people with $\mathrm{CF}$ with advanced pulmonary disease provide the opportunity to focus on the benefit of CFTR modulation in people with CF with severe lung dysfunction. While the initial trial does not provide data for the subset of participants with severe lung disease, it does report that the overall treatment effect was similar among individuals with lung function below and above $70 \%$ predicted.

Following approval and marketing of IVA, several reports of people with CF and severe pulmonary disease treated with IVA were published [7-11]. BARRY et al. [9] reported favourable outcomes of IVA treatment through an extended access programme in 21 adults with severe CF pulmonary disease $\left(\mathrm{FEV}_{1} \%\right.$ pred $<40 \%$ or awaiting lung transplantation) carrying the G551D CFTR mutation. A control group of people with CF with similarly severe lung disease but no G551D mutation, and thus not treated with IVA, served as the control group. In this report, following treatment with IVA, $\mathrm{FEV}_{1} \%$ pred improved by a mean of $4.2 \%$ absolute increase (from $26.5 \%$ to $30.7 \%$; $=0.01$ ) with a median (range) time to best spirometry of 100 (56-160) days. The increase in lung function was also significant compared with the non-G551D control group ( $\mathrm{p}=0.003)$. Mean weight increased from 49.8 to $51.6 \mathrm{~kg}(\mathrm{p}=0.006)$ and days with intravenous (i.v.) antimicrobial treatment decreased from a mean of 23 to $0(\mathrm{p}=0.001)$. Similar efficacy was reported in 14 people with CF with the G551D mutation from Germany [10] and from an expanded access programme from the USA, which also noted a longer time to reach maximal lung function, compared with the historical cohort with preserved lung function [11]. Recently, a report of people with CF with severe disease with non-G551D gating mutations treated with IVA also reported an improvement in lung function, 6-min walk distance, weight and exacerbation frequency [12]. These results are comparable to the overall effect in a randomised controlled trial of IVA in non-G551D mutations (table 1) [13].

In 2015, results of the phase III clinical trial with LUM/IVA in people with CF homozygous for the F508del mutation were published by WAINwRIGHT et al. [14]. This combination of a CFTR corrector (LUM) and the potentiator (IVA) was shown to result in an increase in lung function to a lesser degree than IVA for G551D: an overall 4\% absolute increase in $\mathrm{FEV}_{1} \%$ pred, but a significant $39-61 \%$ reduction in hospitalisations and a $45-56 \%$ reduction in i.v. antibiotic use. In this report, 52 patients who had $\mathrm{FEV}_{1}$ $\%$ pred $<40 \%$ at randomisation were included, and the treatment effect was similar in this group of patients and in the subgroup with moderate to mildly reduced lung function. ELBORN et al. [15] reported a subgroup analysis of people with CF with severely reduced lung function from the TRAFFIC and TRANSPORT studies. This analysis showed an increase (versus placebo) of 3.7 and 3.3 percentage points over placebo in the two dosing groups ( $\mathrm{p}=0.024$ and 0.036 , respectively) and a $9.9-9.1 \%$ relative increase in $\mathrm{FEV}_{1} \%$ pred, also highly clinically significant. Body mass index increased significantly only in one of 
TABLE 1 Summary of effects of cystic fibrosis transmembrane regulator modulators (ivacaftor (IVA), lumacaftor (LUM), tezacaftor (TEZ) and elexacaftor (ELX)) in people with severe lung function impairment from published trials and case series, not including case reports of single patients

\begin{tabular}{|c|c|c|c|c|c|c|c|c|}
\hline First author [ref.] & $\begin{array}{l}\text { Population; study } \\
\text { design: RCT/open }\end{array}$ & $\begin{array}{l}\text { Overall effect: } \\
\text { lung function }\end{array}$ & $\begin{array}{l}\text { Overall effect: } \\
\text { exacerbation } \\
\text { reduction }\end{array}$ & $\begin{array}{l}\text { Patients with severe } \\
\text { disease (FEV } \\
<40 \% \text { pred) }\end{array}$ & $\begin{array}{l}\text { Lung function } \\
\text { increase ( } \% \text { points) } \\
\text { in severe disease }\end{array}$ & $\begin{array}{l}\text { Exacerbation } \\
\text { reduction in } \\
\text { severe disease }\end{array}$ & $\begin{array}{l}\text { Effect on weight or } \\
\text { BMI in severe disease }\end{array}$ & $\begin{array}{l}\text { Effect on quality of } \\
\text { life (mean CFQ-R) } \\
\text { in severe disease }\end{array}$ \\
\hline \multicolumn{9}{|l|}{ IVA } \\
\hline RAMSEY [6] & G551D/any; RCT & $10.6 \%{ }^{\#}$ & $55 \%{ }^{\#}$ & NA & NA & NA & NA & NA \\
\hline De Boeck [13] & $\begin{array}{l}\text { Non-G551D gating/ } \\
\text { any; RCT }\end{array}$ & $10.7 \%^{\#}$ & NA & 0 & NA & NA & NA & NA \\
\hline Hebestreit [10] & $\begin{array}{c}\text { G551D/any; open, } \\
\text { EAP }\end{array}$ & NA & NA & $14(100 \%)$ & $\begin{array}{l}5.2 \pm 5.6^{\pi} ; \text { median } \\
3.9(-4.1-16.8)^{+}\end{array}$ & NA & $\begin{array}{c}2.1 \pm 2.4 \mathrm{~kg}^{\text {I] }} \text { median } 1.1 \\
(-0.3-6.3) \mathrm{kg}^{+}\end{array}$ & NA \\
\hline BARRY [9] & $\begin{array}{c}\text { G551D/any; open, } \\
\text { EAP }\end{array}$ & NA & NA & $21(100 \%)$ & $4.2^{\S}$ & $49 \% \S, f$ & $\begin{array}{c}1.8 \mathrm{~kg}^{\S} ; \text { median } \\
2.3(-0.4-4.2) \mathrm{kg}^{+}\end{array}$ & NA \\
\hline $\begin{array}{l}\text { TAYLOR-COUSAR } \\
\text { [11] }\end{array}$ & $\begin{array}{c}\text { G551D/any; open, } \\
\text { EAP }\end{array}$ & NA & NA & $44(100 \%)$ & $\begin{array}{c}4.8 \pm 0.5^{\uparrow} ; \\
(-13.1-22.7)^{+}\end{array}$ & NA & $\begin{array}{c}3.3 \pm 4.0 \mathrm{~kg}^{\text {97; }} \\
(-2.3-14.4) \mathrm{kg}^{+}\end{array}$ & NA \\
\hline Salvatore [12] & $\begin{array}{l}\text { Non-G551D gating/ } \\
\text { any; open, EAP }\end{array}$ & NA & NA & $13(100 \%)$ & $11.5^{\S}$ & $51 \%$ §. ๆๆ & $3.0 \mathrm{~kg}^{\S}$ & NA \\
\hline \multicolumn{9}{|l|}{ LUM/IVA } \\
\hline $\begin{array}{l}\text { WAINRIGHT [14] } \\
\text { and ELBORN [15] }\end{array}$ & $\begin{array}{l}\text { F508del/F508del; } \\
\text { RCT, subgroup } \\
\text { analysis }\end{array}$ & $2.6-4.0 \%^{\#}$ & $39-61 \%{ }^{\#}$ & $81(7.3 \%)$ & $\begin{array}{l}3.3(0.2-6.4)- \\
3.7(0.5-6.9)^{\#,++}\end{array}$ & $53-41 \%{ }^{\#, \S}$ & $\begin{array}{l}\text { BMI } 0.3(-0.2-0.8) \text { and } \\
0.6(0.1-1.2) \mathrm{kg} \cdot \mathrm{m}^{-2 \#,++}\end{array}$ & $\begin{array}{l}3.3(5.2-11.7) \text { and } \\
-4.2(-12-3.7)^{\#,++}\end{array}$ \\
\hline HUBERT [16] & $\begin{array}{l}\text { F508del/F508del; } \\
\text { open }\end{array}$ & NA & NA & $\begin{array}{c}53 \text { (37 completed } \\
3 \text { months) }\end{array}$ & $3.19^{\S}$ & NA & BMI $0.03 \mathrm{~kg} \cdot \mathrm{m}^{-2 \S}$ & NA \\
\hline $\begin{array}{l}\text { TAYLOR-COUSAR } \\
{[17]}\end{array}$ & $\begin{array}{l}\text { F508del/F508del; } \\
\text { open }\end{array}$ & NA & NA & $\begin{array}{c}46 \text { (35 completed } \\
24 \text { weeks) }\end{array}$ & $-0.4(-1.9-1.1)^{\#,++}$ & $64 \%$ ร. ๆาा & $\begin{array}{c}\text { BMI } 0.29 \\
(0.17) \mathrm{kg} \cdot \mathrm{m}^{-2 \S,++}\end{array}$ & $2.5(-1.0-5.9)^{++}$ \\
\hline MURER [18] & $\begin{array}{l}\text { F508del/F508del; } \\
\text { open }\end{array}$ & NA & NA & 20 (10 completed) & $+2.5^{\# \#}$ & $60 \%$ §.าๆๆ & BMI $0.9 \mathrm{~kg} \cdot \mathrm{m}^{-2 \# \#}$ & NA \\
\hline DIAB-CÁCERES [19] & $\begin{array}{l}\text { F508del/F508del; } \\
\text { open }\end{array}$ & NA & NA & 20 & & $61 \%$ §.ๆๆ & & \\
\hline \multicolumn{9}{|l|}{ TEZ/IVA } \\
\hline $\begin{array}{l}\text { TAYLOR-COUSAR } \\
\text { [21] }\end{array}$ & $\begin{array}{l}\text { F508del/F508del; } \\
\text { RCT }\end{array}$ & $\begin{array}{c}4.0 \\
(3.1-4.8)^{\#,++}\end{array}$ & $36 \%{ }^{\#,++}$ & $27(9.4 \%)$ & $3.5(1.0-6.1)^{\#,++}$ & NA & NA & NA \\
\hline Rowe [22] & $\begin{array}{l}\text { F508del/RF; RCT } \\
\text { (crossover) }\end{array}$ & $\begin{array}{c}6.8 \\
(5.7-7.8)^{\#,++}\end{array}$ & $46 \%$ & $22(9 \%)$ & $4.4(1.1-7.8)^{\#,++}$ & NA & NA & NA \\
\hline \multicolumn{9}{|l|}{ ELX/TEZ/IVA } \\
\hline MidDLEton [23] & F508del/MF; RCT & $\begin{array}{c}13.8 \\
(12.1-15.4)^{\#,++}\end{array}$ & $63 \%$ & $18(9 \%)$ & $15.2(7.3-23.1)^{\#,++}$ & NA & NA & NA \\
\hline \multicolumn{9}{|c|}{ 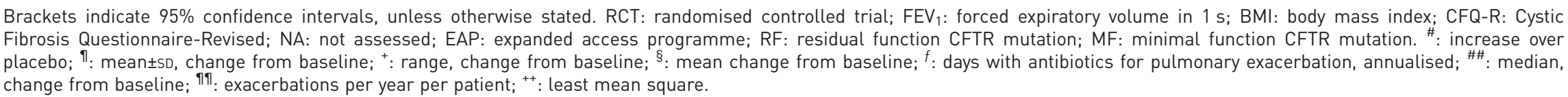 } \\
\hline
\end{tabular}


the dosing groups (600 mg LUM) and results of a quality-of-life questionnaire were not significantly improved. Exacerbations and events necessitating i.v. treatment were reduced, reaching statistical significance in the $600 \mathrm{mg}$ LUM group.

Post-marketing of LUM/IVA, several open-label studies reported results of treatment in people with CF homozygous for F508del with severe lung disease $\left(\mathrm{FEV}_{1} \%\right.$ pred $\left.<40 \%\right)$ commencing treatment with LUM/IVA (table 1) [16-20]. Collectively, these case series report a reduction in exacerbation frequency. Some of these series also demonstrate improvement in lung function, nutritional status and quality of life; however, the results did not uniformly reach statistical significance.

Following the development of LUM/IVA, and due to drug-related adverse respiratory events discussed in the following sections, a second CFTR corrector, TEZ, was developed. The combined corrector/potentiator TEZ/IVA was evaluated in two clinical trials. The EVOLVE trial compared TEZ/IVA with placebo in people with CF homozygous for F508del [21]. The EXPAND trial was a shorter (8 weeks) crossover trial comparing TEZ/IVA, IVA alone and placebo in compound heterozygotes with one F508del mutation and one pre-specified "residual function" CFTR mutation in cis (CFTR that allows some chloride transport and/or shown to be responsive to IVA in vitro) [22]. In both studies, a subanalysis of patients with $\mathrm{FEV}_{1}$ $\%$ pred $<40 \%$ was performed. In the EVOLVE study there was an overall increase in lung function of $4 \%$ and a $35 \%$ reduction in pulmonary exacerbations. 24 people with $\mathrm{FEV}_{1} \%$ pred $<40 \%$ had an increase in lung function, similar to the overall effect observed in the study (absolute increase 3.5\%, 95\% CI 1.0 $6.1 \%)$. The EXPAND crossover trial showed an overall absolute increase of $6.8 \%$ in $\mathrm{FEV}_{1} \%$ pred over placebo, with $9 \%$ of patients with $\mathrm{FEV}_{1} \%$ pred $<40 \%$ at randomisation showing a significant increase of 4.4 (95\% CI 1.1-7.8) percentage points.

Both TEZ/IVA and LUM/IVA had effects on lung function that were modest compared with the effects of IVA on people with gating mutations. The addition of a second corrector, ELX, to TEZ/IVA resulted in improved CFTR function in excess of the TEZ/IVA effect. In clinical trials of treating people with CF with one or two F508del alleles, the ELX/TEZ/IVA combination led to a markedly improved lung function gain of $10-14 \%[23,24]$, with a reduction of exacerbations by $63 \%$ [23]. People with $\mathrm{FEV}_{1} \%$ pred $<40 \%$ gained lung function $\left(\mathrm{FEV}_{1} \%\right.$ pred) by of a mean 15.2\% (95\% CI 7.3-23.1\%) (absolute) over placebo [23].

Table 1 summarises the overall effects and those in the subgroup of people with CF with severe disease in randomised trials and case series of CFTR modulators.

\section{Adverse events resulting from CFTR modulator therapy in people with CF with severe lung disease}

The IVA studies demonstrated a favourable safety profile, with adverse events similar in frequency between the placebo and active treatment arms [6]. In the LUM/IVA trials, however, two adverse events emerged with an increased frequency compared with placebo: dyspnoea, reported in 13.0-14.9\% of trial participants on active treatment versus $7.8 \%$ on placebo, and "abnormal respiration" (the term for chest tightness), reported in $8.7-10.8 \%$ of trial participants on active treatment versus $5.9 \%$ on placebo [14]. In the clinical trial, these adverse events were generally well tolerated, as $96.3 \%$ of people with severe disease completed 24 weeks of the study. In people with CF with severe disease, the frequencies of these events were even higher: $26.4 \%$ of participants with $\mathrm{FEV}_{1} \%$ pred $<40 \%$ on active treatment reported dyspnoea (versus $14.3 \%$ of participants with severe disease on placebo) and $7.5 \%$ versus $3.5 \%$ reported "abnormal respiration" [15]. These events were also common in studies reporting on open-label administration in people with CF with severe disease, with rates of adverse events as high as $75 \%$ (table 2). In up to $35 \%$ of people with CF with severe disease, adverse events were not tolerated and led to treatment discontinuation. One possible explanation for the higher frequency of treatment discontinuation in "real-life" trials may be the greater severity of disease than in participants eligible for clinical trials. This difference highlights the importance of post-marketing studies in investigating effects of new drugs outside of a clinical trial setting.

In a study by Popowicz et al. [25], spirometry was performed immediately before the first administration of LUM/IVA, and subsequently repeated 2 and $24 \mathrm{~h}$ following the first administration of LUM/IVA. Results showed an acute mean $19 \%$ decrease in $\mathrm{FEV}_{1} \%$ pred of a following LUM/IVA administration (range $-21-11 \% ; \mathrm{p}=0.001$ ), which persisted after $24 \mathrm{~h}$ and returned to baseline in $83 \%$ of patients when next measured 1 month after the first dose. Post-dose spirometry was also performed at 2, 4-6 and $24 \mathrm{~h}$ subsequent to LUM/IVA dosing in the randomised trial of LUM/IVA in children 6-11 years old, in which only 11 out of 204 (5\%) children had a baseline $\mathrm{FEV}_{1} \%$ pred $<70 \%$. Following LUM/IVA dosing on day 1, participants' mean post-dose $\mathrm{FEV}_{1} \%$ pred was $-5.5 \%$ at $\leqslant 2 \mathrm{~h},-7.7 \%$ at $4-6 \mathrm{~h}$ and -4.1 at $24 \mathrm{~h}$ [26]. A real-life study similarly found an acute drop in lung function in LUM/IVA-treated children aged $15.5 \pm 1.6$ years with a wide range of initial lung function, which was inversely correlated with initial $\mathrm{FEV}_{1}$ $\%$ pred and directly correlated with bronchodilator reversibility [27]. 
TABLE 2 Summary of the frequency of adverse events (dyspnoea and "abnormal respiration") in clinical trials and case series of lumacaftor (LUM)/ivacaftor (IVA) in people with advance cystic fibrosis lung disease

\begin{tabular}{|c|c|c|c|c|c|}
\hline First author [ref.] & $\begin{array}{c}\text { Type of } \\
\text { trial }\end{array}$ & Patients & $\begin{array}{l}\text { Patients with } \\
\text { FEV }_{1}<40 \% \\
\text { pred }\end{array}$ & $\begin{array}{c}\text { Adverse event frequency } \\
\text { in } \mathrm{FEV}_{1}<40 \% \text { : dyspnoea/ } \\
\text { abnormal respiration }\end{array}$ & $\begin{array}{l}\text { Discontinued } \\
\text { LUM/IVA }\end{array}$ \\
\hline $\begin{array}{l}\text { ELBORN [15] } \\
\text { (TRAFFIC AND } \\
\text { TRANSPORT) }\end{array}$ & RCT & 1072 & 81 & $14(26) / 4(8)^{\#}$ & $3(3.4)$ \\
\hline Popowicz [25] & $\begin{array}{l}\text { Open } \\
\text { label }\end{array}$ & NA & 12 & $8(75)$ & $3(25)$ \\
\hline Hubert [16] & $\begin{array}{l}\text { Open } \\
\text { label }\end{array}$ & NA & 53 & $27(51)$ & $13(24)$ \\
\hline Jennings [20] & $\begin{array}{l}\text { Open } \\
\text { label }\end{array}$ & 116 & 19 & $11(58)$ & $6(32)$ \\
\hline TAYLOR-Cousar [17] & $\begin{array}{l}\text { Open } \\
\text { label }\end{array}$ & NA & 48 & $20(43) / 26(57)$ & $8(17)$ \\
\hline MURER [18] & $\begin{array}{l}\text { Open } \\
\text { label }\end{array}$ & NA & 20 & $1(5) / 1(5)^{\#}$ & 1 (5) \\
\hline DiaB-CÁceres [19] & $\begin{array}{l}\text { Open } \\
\text { label }\end{array}$ & NA & 20 & 15 (75) & 7 (35) \\
\hline
\end{tabular}

Data are presented as $\mathrm{n}$ or $\mathrm{n}(\%)$. RCT: randomised controlled trial; $\mathrm{FEV}_{1}$ : forced expiratory volume in $1 \mathrm{~s}$; NA: not available. ${ }^{\#}$ : dyspnoea/chest tightness only.

The mechanism of the acute adverse effect on lung function, which may be the cause of the clinical phenomena, is not known. LUM may result in bronchospasm, and thus an immediate and symptomatic drop in lung function. Alternatively, it was hypothesised to be a "target effect": LUM/IVA administration resulting in increased CFTR activity and thus causing mucus to be propelled into airways, temporarily causing an obstruction until eventually cleared [15]. If this mechanism explained the phenomenon, a similar effect should also be seen with TEZ/IVA, which activates CFTR to a similar degree in F508 homozygotes. However, in the EVOLVE and EXPAND trials (the phase III studies in which TEZ/IVA was evaluated), dyspnoea and abnormal respiration were reported at the same frequency in the active and placebo arms overall, and in the group with severe lung dysfunction. In both TEZ/IVA studies, lung function was measured before and 2 and $4 \mathrm{~h}$ after the first dose, and on day 15 an acute drop in lung function was not observed in either study [21, 22]. Adverse events with ELX/TEZ/IVA that were more common in active groups than placebo were not increased in people with severe disease [23, 24]. Hence, the cause of lung function decline and respiratory symptoms associated with LUM/IVA are more likely due to a unique effect not shared by TEZ/IVA.

\section{Drug-drug interactions}

Metabolism of the newly developed CFTR modulators is mainly by the cytochrome P450 (CYP) family of enzymes. Thousands of CYP subtypes of this family of enzymes are known in nature, but only 15 are relevant in human metabolism [28]. Cytochrome enzymes may be induced, i.e. expression of the relevant gene increased, by several drugs (usually, but not only, substrates of the same cytochrome). They may also be inhibited, either competitively or noncompetitively. Induction of any cytochrome may result in enhanced metabolism, and thus faster elimination and lower levels, of its substrate compounds. Inhibition results in the opposite effect, i.e. increased drug levels.

The P450 subtypes CYP3A4 and CYP3A5 metabolise IVA to its less active metabolite M1 and its inactive metabolite M6, TEZ to its less active metabolites M1, M2 and M5, and ELX to a less active metabolite, M23-ELX; LUM levels are unchanged by CYP3A [29, 30]. LUM as well as several drug compounds (excluding TEZ, but including to a small extent IVA and its less active metabolite) induce CYP3A expression; there are a number of drugs, including azole antifungals, that inhibit CYP3A (figure 1). LUM also induces and inhibits several other CYP subtypes (induction: CYP3A, CYP2B6, CYP2C8, CYP2C9 and CYP2C19; inhibition: CYP2C8 and CYP2C9). The induction and inhibition of CYP enzymes may result in significant drug-drug interactions with several classes of compounds, including, but not limited to, antimicrobials (rifampin, isoniazid, bedaquiline and voriconazole), proton pump inhibitors (omeprazole), antidepressants (fluoxetine), anticonvulsives (phenytoin), oral contraceptives and warfarin. Drug-drug 


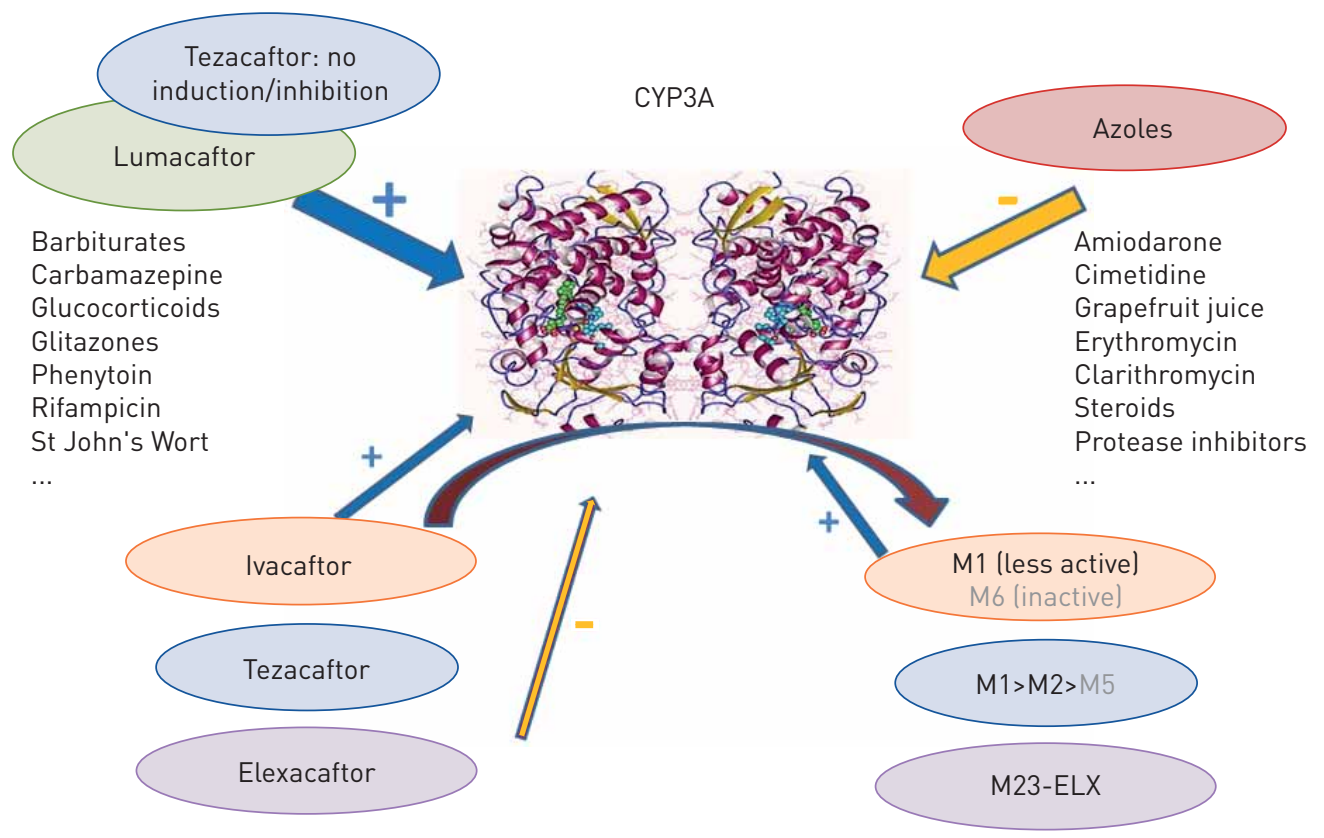

FIGURE 1 A summary of interactions between cystic fibrosis transmembrane regulator modulators and other drugs/compounds and cytochrome P450 3A4 (CYP3A). Blue arrows: induction of the cytochrome; yellow arrow: inhibition of the cytochrome; curved arrow: metabolism of a drug by the cytochrome. Adapted from [28-32].

interactions may also exist with the use of TEZ, ELX and IVA, mainly strong and moderate inhibitors of CYP3A. Concomitant use of both of these drug classes may result in increased serum levels of IVA (to 15 times the therapeutic level) and TEZ (to 4 times the therapeutic level). While it is not known what the implications of elevated levels of these drugs may be based solely on animal toxicology data, caution is warranted and hence a reduction of ELX, TEZ and IVA doses is recommended [31, 32]. ELX is an inhibitor of other cytochrome subtypes (CYP1A2, CYP2B6, CYP2C8, CYP2C9, CYP2C19 and CYP2D6) and also of organic anion transporters $1 \mathrm{~B} 1$ and 1B3. It is carried in blood by albumin, and thus may displace other drugs (e.g. digoxin) and increase their levels [30, 32].

In summary, while drug-drug interactions are complex and numerous with LUM, for TEZ, IVA and ELX, dose reductions are recommended with CYP3A inhibitors, but otherwise there is a smaller risk for drug-drug interactions than with LUM.

\section{Conclusions}

The CFTR modulators IVA, LUM/IVA, TEZ/IVA and ELX/TEZ/IVA have a beneficial effect not only in individuals with mild to moderate $\mathrm{CF}$, but also in individuals with advanced pulmonary disease, including candidates for lung transplantation. This beneficial impact was clearly demonstrated by randomised controlled trials (for those subjects who met lung function criteria at enrolment, but whose lung function declined to below the qualifying $\mathrm{FEV}_{1} \%$ pred by the randomisation visit) as well as in open-label studies, which generally enrolled people with greater severity of pulmonary disease than those inadvertently included in the randomised controlled trials.

Compared with LUM/IVA, TEZ/IVA administration has the advantage of fewer adverse events and drugdrug interactions, making this drug combination the better choice for use in triple combination therapy for people with F508del CF $[33,34]$. The improved tolerability profile of TEZ/IVA is especially important in individuals with severe pulmonary disease, in many of whom severe adverse effects of LUM/IVA precluded its use. It is also important that TEZ/IVA is more compatible than LUM/IVA with the complexity of chronic medication regimens of many individuals with advanced pulmonary disease.

It is acknowledged that the most substantial impact of CFTR modulator therapy will likely be observed when started as early as possible in the course of disease, at a time when irreversible lung damage is minimal. However, ample evidence currently exists to justify the use of CFTR modulator treatment in people with established, advanced lung disease. With the recent US Federal Drug Administration approval of highly effective triple combination therapy for the majority of individuals with CF [32], we may expect more people with severe CF pulmonary disease to gain life-changing benefit from CFTR modulation. 
Conflict of interest: M. Shteinberg reports grants, personal fees and nonfinancial support from GSK, grants and nonfinancial support from Novartis and Trudell, nonfinancial support from Actelion, and personal fees from Boehringer Ingelheim, AstraZeneca and Vertex, outside the submitted work. J. Taylor-Cousar reports grants and personal fees from Vertex, Proteostasis and Celtaxys, and personal fees from Gilead, Santhera and Protalix, outside the submitted work. She serves on the CF TDN Clinical Research Executive Committee and is Chair-Elect of the ATS Clinical Problems Assembly Programming Committee.

\section{References}

1 Rosenfeld M, Wainwright CE, Higgins M, et al. Ivacaftor treatment of cystic fibrosis in children aged 12 to $<24$ months and with a CFTR gating mutation (ARRIVAL): a phase 3 single-arm study. Lancet Respir Med 2018; 6: 545-553.

2 McNamara JJ, McColley SA, Marigowda G, et al. Safety, pharmacokinetics, and pharmacodynamics of lumacaftor and ivacaftor combination therapy in children aged 2-5 years with cystic fibrosis homozygous for F508del-CFTR: an open-label phase 3 study. Lancet Respir Med 2019; 7: 325-335.

3 Stalvey MS, Pace J, Niknian M, et al. Growth in prepubertal children with cystic fibrosis treated with ivacaftor. Pediatrics 2017; 139: e20162522.

4 Cystic Fibrosis Foundation. Cystic Fibrosis Foundation Patient Registry 2017 Annual Data Report. 2018. www.cff. org/Research/Researcher-Resources/Patient-Registry/2017-Patient-Registry-Annual-Data-Report.pdf Date last accessed: August 16, 2019.

5 Martin C, Hamard C, Kanaan R, et al. Causes of death in French cystic fibrosis patients: the need for improvement in transplantation referral strategies! J Cyst Fibros 2016; 15: 204-212.

6 Ramsey BW, Davies J, McElvaney NG, et al. A CFTR potentiator in patients with cystic fibrosis and the G551D mutation. N Engl J Med 2011; 365: 1663-1672.

7 Harrison MJ, Murphy DM, Plant BJ. Ivacaftor in a G551D homozygote with cystic fibrosis. N Engl J Med 2013; 369: $1280-1282$.

8 Polenakovik HM, Sanville B. The use of ivacaftor in an adult with severe lung disease due to cystic fibrosis (AF508/G551D). J Cyst Fibros 2013; 12: 530-531.

9 Barry PJ, Plant BJ, Nair A, et al. Effects of ivacaftor in patients with cystic fibrosis who carry the G551D mutation and have severe lung disease. Chest 2014; 146: 152-158.

10 Hebestreit H, Sauer-Heilborn A, Fischer R, et al. Effects of ivacaftor on severely ill patients with cystic fibrosis carrying a G551D mutation. J Cyst Fibros 2013; 12: 599-603.

11 Taylor-Cousar J, Niknian M, Gilmartin G, et al. Effect of ivacaftor in patients with advanced cystic fibrosis and a G551D-CFTR mutation: safety and efficacy in an expanded access program in the United States. J Cyst Fibros 2016; 15: 116-122

12 Salvatore D, Carnovale V, Iacotucci P, et al. Effectivenesss of ivacaftor in severe cystic fibrosis patients and non-G551D gating mutations. Pediatr Pulmonol 2019; 54: 1398-1403.

13 De Boeck K, Munck A, Walker S, et al. Efficacy and safety of ivacaftor in patients with cystic fibrosis and a non-G551D gating mutation. J Cyst Fibros 2014; 13: 674-680.

14 Wainwright CE, Elborn JS, Ramsey BW, et al. Lumacaftor-ivacaftor in patients with cystic fibrosis homozygous for Phe508del CFTR. N Engl J Med 2015; 373: 220-231.

15 Elborn JS, Ramsey BW, Boyle MP, et al. Efficacy and safety of lumacaftor/ivacaftor combination therapy in patients with cystic fibrosis homozygous for Phe508del CFTR by pulmonary function subgroup: a pooled analysis. Lancet Respir Med 2016; 4: 617-626.

16 Hubert D, Chiron R, Camara B, et al. Real-life initiation of lumacaftor/ivacaftor combination in adults with cystic fibrosis homozygous for the Phe508del CFTR mutation and severe lung disease. J Cyst Fibros 2017; 16: 388-391.

17 Taylor-Cousar JL, Jain M, Barto TL, et al. Lumacaftor/ivacaftor in patients with cystic fibrosis and advanced lung disease homozygous for F508del-CFTR. J Cyst Fibros 2018; 17: 228-235.

18 Murer C, Huber LC, Kurowski T, et al. First experience in Switzerland in Phe508del homozygous cystic fibrosis patients with end-stage pulmonary disease enrolled in a lumacaftor-ivacaftor therapy trial - preliminary results. Swiss Med Wkly 2018; 148: w14593.

19 Diab-Cáceres L, Girón-Moreno RM, Pastor-Sanz MT, et al. Compassionate use of lumacaftor/ivacaftor in cystic fibrosis: Spanish experience. Arch Bronconeumol 2018; 54: 614-618.

20 Jennings MT, Dezube R, Paranjape S, et al. An observational study of outcomes and tolerances in patients with cystic fibrosis initiated on lumacaftor/ivacaftor. Ann Am Thorac Soc 2017; 14: 1662-1666.

21 Taylor-Cousar JL, Munck A, McKone EF, et al. Tezacaftor-ivacaftor in patients with cystic fibrosis homozygous for Phe508del. N Engl J Med 2017; 377: 2013-2023.

22 Rowe SM, Daines C, Ringshausen FC, et al. Tezacaftor-ivacaftor in residual-function heterozygotes with cystic fibrosis. N Engl J Med 2017; 377: 2024-2035.

23 Middleton PG, Mall MA, Dřevínek P, et al. Elexacaftor-tezacaftor-ivacaftor for cystic fibrosis with a single Phe508del allele. N Engl J Med 2019; 381: 1809-1819.

24 Heijerman HGM, McKone EF, Downey DG, et al. Efficacy and safety of the elexacaftor plus tezacaftor plus ivacaftor combination regimen in people with cystic fibrosis homozygous for the F508del mutation: a double-blind, randomised, phase 3 trial. Lancet 2019; 394: 1940-1948.

25 Popowicz N, Wood J, Tai A, et al. Immediate effects of lumacaftor/ivacaftor administration on lung function in patients with severe cystic fibrosis lung disease. J Cyst Fibros 2017; 16: 392-394.

26 Ratjen F, Hug C, Marigowda G, et al. Efficacy and safety of lumacaftor and ivacaftor in patients aged 6-11 years with cystic fibrosis homozygous for F508del-CFTR: a randomised, placebo-controlled phase 3 trial. Lancet Respir Med 2017; 5: 557-567.

27 Labaste A, Ohlmann C, Mainguy C, et al. Real-life acute lung function changes after lumacaftor/ivacaftor first administration in pediatric patients with cystic fibrosis. J Cyst Fibros 2017; 16: 709-712.

28 Coleman MD. How Oxidative Systems Metabolize Substrates. Human Drug Metabolism: An Introduction. 2nd Edn. New York, Wiley, 2010; pp. 23-64. 
29 Schneider EK. Cytochrome P450 3A4 induction: lumacaftor versus ivacaftor potentially resulting in significantly reduced plasma concentration of ivacaftor. Drug Metab Lett 2018; 12: 71-74.

30 Wishart DS, Knox C, Guo AC, et al. DrugBank: a knowledgebase for drugs, drug actions and drug targets. Nucleic Acids Res 2008; 36: D901-D906.

31 Food and Drug Administration. SYMDEKO drug insert. 2018. www.accessdata.fda.gov/drugsatfda_docs/label/ 2018/210491lbl.pdf Date last accessed: July 12, 2019.

32 Food and Drug Administration. TRIKAFTA drug insert. 2019. www.accessdata.fda.gov/drugsatfda_docs/label/ 2019/212273s000lbl.pdf Date last accessed: January 22, 2020.

33 Keating D, Marigowda G, Burr L, et al. VX-445-tezacaftor-ivacaftor in patients with cystic fibrosis and one or two Phe508del alleles. N Engl J Med 2018; 379: 1612-1620.

34 Taylor-Cousar JL, Mall MA, Ramsey BW, et al. Clinical development of triple-combination CFTR modulators for cystic fibrosis patients with one or two F508del alleles. ERJ Open Res 2019; 5: 00082-2019. 